\title{
Dunas litorais
}

\author{
A. M. Galopim de Carvalho \\ Universidade de Lisboa \\ amgalopimdecarvalho@gmail.com
}

\section{CITAÇÃO \\ Galopim de Carvalho, A.M., (2018) \\ Dunas litorais, \\ Rev. Ciência Elem., V6(03):058. \\ doi.org/10.24927/rce2018.058}

\section{EDITOR}

José Ferreira Gomes,

Universidade do Porto

\section{EDITOR CONVIDADO}

João Lopes dos Santos,

Universidade do Porto

\section{RECEBIDO EM}

29 de julho de 2018

\section{ACEITE EM}

29 de julho de 2018

\section{PUBLICADO EM}

04 de outubro de 2018

\section{COPYRIGHT}

(C) Casa das Ciências 2018.

Este artigo é de acesso livre, distribuído sob licença Creative Commons com a designação CC-BY-NC-SA 4.0, que permite a utilização e a partilha para fins não comerciais, desde que citado o autor e a fonte original do artigo.

rce.casadasciencias.org
As edificações dunares não são exclusivas dos desertos de areia. Existem nas orlas litorais anamórficas, em qualquer latitude, sempre que a extensão do areal da praia, a seco, seja suficiente, e haja vento soprado do lado do mar $^{1}$.

Nas praias, os ventos dominantes, quando animados de energia suficiente, varremthes as areias com as quais alimentam as acumulações dunares, fazendo-as progredir para o interior, invadindo as terras de cultivo, sendo conhecidas velocidades de progressão dunar na ordem dos $25 \mathrm{~m} /$ ano. Desde que a topografia o permita, as dunas assumem grandes extensões, no geral, paralelas à costa, constituindo cordões que, por vezes, se alargam alguns quilómetros para o interior, podendo atingir alturas na ordem da centena de metros, como é o caso da duna do Pilat $(114 \mathrm{~m})$, a sul de Arcachon, na costa das Landes (França), onde o complexo dunar litoral tem mais de 225 km de comprimento por $5 \mathrm{~km}$ de largura. Em Portugal, as dunas litorais, também conhecidas por medos ou medões, alongam-se, com interrupções, entre Espinho e Vila Nova de Milfontes, na costa ocidental, e na orla algarvia.

Nas dunas litorais trava-se um confronto constante entre a progressão da areia e a ocupação vegetal que se lhe opõe. Por falta de alimentação (na praia), ou quando a velocidade do vento abranda e, portanto, a sua capacidade de transporte diminui, a vegetação inicia a sua fixação e tende a alastrar, o que constitui um entrave à deflação (ação de varrimento pelo vento), incrementando-se a ocupação vegetal, até que a duna se fixa. Pelo contrário, nas áreas mais expostas às ações do vento e desde que haja areia disponível, a sua constante movimentação não permite a fixação das plantas e a duna cresce e progride. A duna litoral é, pois, uma entidade instável, onde as ações (do vento e da vegetação) se neutralizam, e que oscila em função das variações ocasionais, resultando numa fronteira natural entre a praia e o interior. 0 Homem pode intervir na deslocação desta fronteira, a seu favor, através de artifícios vários. Para além de fornecer madeira, sobretudo para a construção naval, o pinhal de Leiria (plantado muito antes do tempo do rei D. Dinis e destruído em 2017 por incendiários criminosos), conteve a progressão dunar para o interior.

Habitualmente, por desconhecimento ou por negligência, o homem intervém neste equilíbrio, com consequências adversas para o ambiente natural, a médio ou a longo prazo, sempre lesivas dos seus interesses. A extração de areias nas praias ou nas dunas, a implantação de construções nestes edifícios móveis ou o trânsito de pessoas e viaturas são causas de situações indesejáveis, frequentemente noticiadas e documentadas por convincentes imagens televisivas.

As dunas litorais, uma vez que são alimentadas pelas areias das praias, têm, em prin- 
cípio, composição muito semelhante à destas, apresentando, todavia, melhor calibragem. Por outro lado, a composição mineralógica evidencia seleção gravítica, pois, face ao soprar do vento, vão ficando para trás os grãos de areia das espécies mais densas, que permanecem na praia como concentrados residuais do tipo "placer". É o que acontece, nomeadamente na praia de São Torpes, a sul de Sines, localmente enriquecida em ilmenite e magnetite, dois minerais adjetivados de "pesados", provenientes da erosão de rochas ígneas básicas do maciço magmático de Sines (gabro, diorito e sienito), parcialmente exposto à erosão subaérea e à das vagas no litoral. Assim, a areia das dunas é essencialmente constituída pelos minerais ditos "leves" (maioritariamente quartzo e algum feldspato) a que se associa uma certa percentagem de bioclastos (grãos mais ou menos rolados de fragmentos de conchas) de natureza calcária. 0 transporte pelo vento, dito eólico (de Éolo, deus grego dos ventos), faz com que os grãos de quartzo da areia subtraídos à praia choquem entre si, despolindo a superfície.

Em dunas com 1 a 2 milhões de anos, estes bioclastos são total ou parcialmente dissolvidos por ação da água das chuvas (ricas em dióxido de carbono), que percorre o interior do corpo dunar, caracterizado por elevada porosidade. 0 carbonato de cálcio resultante dessa dissolução reprecipita depois, contribuindo, juntamente com outros fatores, para a cimentação dos grãos de areia. Formam-se, assim, dunas consolidadas ou dunas fósseis, em que os grãos se encontram colados uns aos outros através de uma película calcária que os envolve. Perto de Lisboa, em Oitavos, entre Cascais e o Guincho, encontra-se uma esplêndida duna consolidada, escavada do lado virado a leste, permitindo a observação de pormenor da estratificação entrecruzada, do carácter poroso e da deficiente consolidação desta rocha. Outras dunas consolidadas estão parcialmente conservadas na nossa costa, no Magoito e entre Sines e Porto Covo. A itha do Pessegueiro é formada por dunas consolidadas, e o forte em ruínas, que the fica em frente, foi construído com blocos desta rocha.

A ilha de Porto Santo, na sua parte central, está coberta por uma formação arenosa transportada eolicamente para norte, a partir do areal da praia, a sul (FIGURA 1). Estes eoleanitos, assim se podem chamar, em virtude do agente que os transportou, são constituídos por areias calcárias essencialmente biogénicas, geradas numa plataforma carbonatada, que aí se desenvolveu no Miocénico, em condições de clima mais quente do que o atual. Móveis, na franja dunar da praia, a sul, estas areias estão mais ou menos consolidadas a norte da ilha, na região de Mornos e na Fonte da Areia. Aspetos semelhantes, mas em menor escala, podem ser observados na ponta de S. Lourenço, na ilha da Madeira.

São muitos os exemplos de acumulações dunares no passado geológico, hoje transformadas em arenitos ou grés, mais ou menos coesos, no geral penetrados por um cimento argiloso ou calcário, com maior ou menor impregnação de óxido de ferro (vermelho) e, algumas vezes, silicioso. Abstração feita ao cimento, que é sempre posterior à acumulação eólica, as areias destas rochas mostram as mesmas características mineralógicas, texturais e estruturais das dunas recentes. Entre as muitas ocorrências destes arenitos, merecem destaque os Navajo Sandstones do Jurássico, no Utah, (EUA), parte dos New Red Sandstones, do Permo-Triásico (Rotliegende e Buntsandstein) da Europa e da América do Norte, os grés do Câmbrico inferior da Suécia e os arenitos da Formação Botucatu do Mesozoico do Paraná, Brasil. 


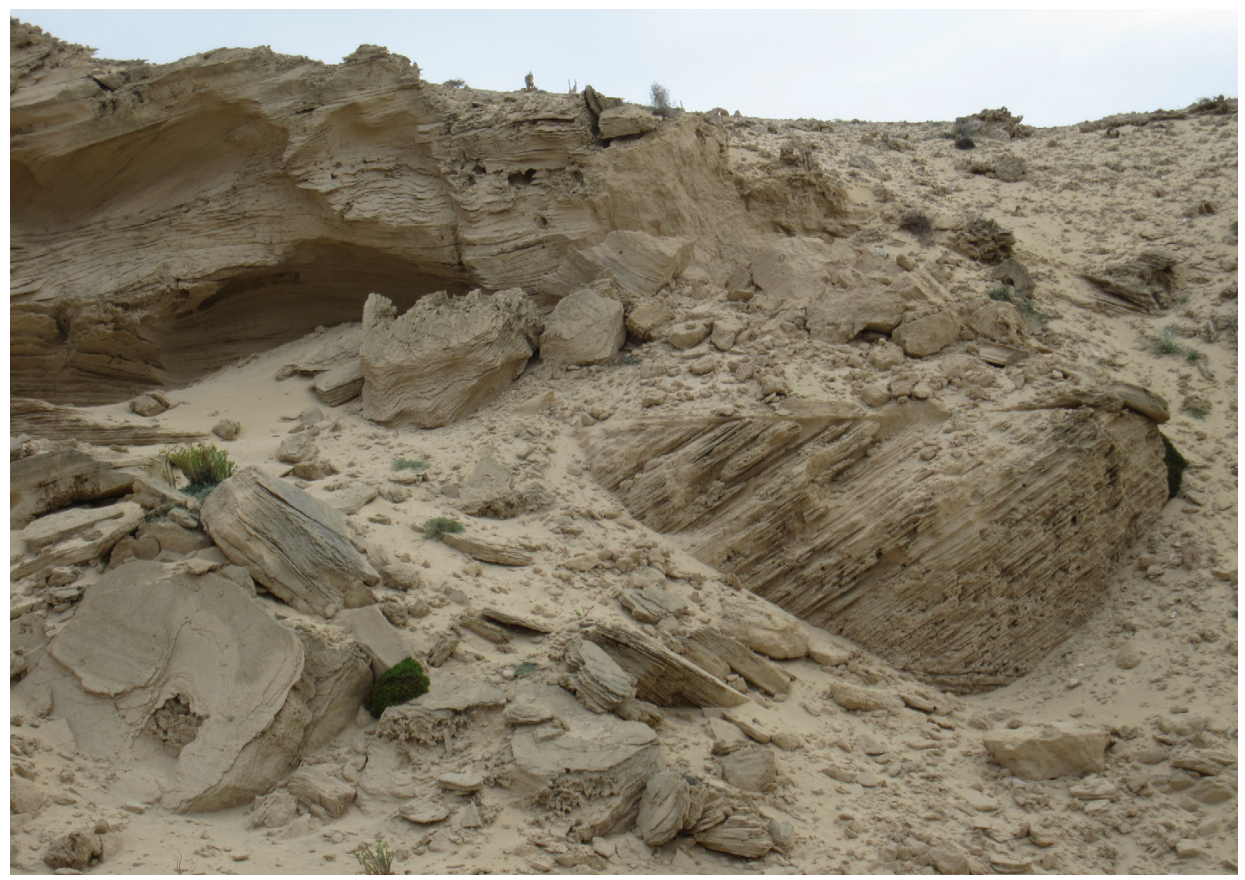

FIGURA 1. Aspeto dos eoleanitos de Porto Santo, num corte de cerca de 3 metros ao longo da estrada. (fonte: banco de imagens da Casa das Ciências)

A identificação de edifícios dunares, de tempos geológicos passados, baseia-se em aspetos bem definidos e relativamente fáceis de observar: estratificação entrecruzada, com múltiplas direções e inclinações (à volta de $30 \%$ ), bem conhecidas nas dunas atuais, lâminas bem individualizadas, diâmetro médio dos grãos entre 0,1 e $1 \mathrm{~mm}$, bom arredondamento, aspeto despolido (picotado) dos grãos de diâmetro superior a 0,5 mm e ausência de leitos de argila e de micas.

\section{NOTA:}

Para alguns autores, grés e arenito são sinónimos; para outros o termo (do francês antigo griot ou do alemão Griess) implica um grau de coesão mais acentuado.

"Placer" - depósito natural por concentração de clastos (areia ou cascalho) de minerais com importância económica. É um depósito superficial, concentrado mecanicamente por correntes fluviais, marinhas ou eólicas.

\section{REFERÊNCIAS}

${ }^{1}$ TUCKER, M. E., Sedimentary Petrology: An Introduction to the Origin of Sedimentary Rocks. Blackwell Science, 262p, 2001. 